\title{
Marcin Fortuna*
}

\section{Icelandic post-lexical syllabification and vowel length in CVCV phonology}

DOI 10.1515/tlr-2015-0004

\begin{abstract}
The paper aims at providing a CVCV analysis of the Icelandic syllabification phenomena and the distribution of vocalic quantity. Two syllabification algorithms are reported to exist in Icelandic: lexical and post-lexical (Ârnason 1998, 2011). The article will focus on the post-lexical algorithm, which determines vowel length in derivatives with class 2 suffixation, compounds, and across word boundaries. A modified model of CVCV will be argued for, which combines the insights from Scheer's (2004, 2012) and Cyran's (2003, 2010) model. It will be proposed that phonological computation applies only once to the whole string (preferably the whole sentence) and that the activity of the interface boils down to representational intervention (in accordance with Scheerian Direct Interface). It will be proposed that manipulation of Final Empty Nuclei (at least in the form of distributing parametric government) is a possible interface operation, as assumed in earlier CVCV (Scheer 2004). The complex pattern of two syllabification algorithms in Icelandic arises via an intricate interplay of sonority profiles of consonants and the needs of intervening empty nuclei (some of which are parametrically governed, while some others are not).
\end{abstract}

Keywords: phonology-morphosyntax interface, vowel length, Icelandic, CVCV

\section{Introduction}

Icelandic syllabification and the distribution of vowel length have intrigued linguists for decades. There have been numerous (sometimes complementary, sometimes mutually exclusive) attempts to describe the phenomenon from a variety of different angles (see e.g. Haugen 1958; Vennemann 1972; Árnason 1980, 1998; Murray and Vennemann 1983; Kiparsky 1984; Gussmann 2002, 2006a, 2006b; Gouskova 2004). However, most of the extant approaches focused on the vocalic quantity in individual (and simple) words, disregarding the complex situation found in compounds and post-lexically. In fact, the problem of the distribution of

*Corresponding author: Marcin Fortuna, Ludwig Maximilian University of Munich, Munich, Germany, E-mail: marcin.fortuna@lipp.Imu.de 
vocalic quantity in post-lexical contexts constitutes a much bigger challenge for phonological theory, since it involves an unusual type of the interplay between phonological and morphosyntactic factors.

The present contribution aims at providing a new explanation of this intricate phenomenon, with the discussion being of general relevance for the issue of phonology-morphosyntax interface. The theoretical model to be used is a unique variant of CVCV phonology which combines the insights of Scheer's (2004, 2012a) and Cyran's (2003, 2010) versions of the theory. The proposed framework eliminates internuclear government (retaining at the same time internuclear licensing) and establishes consonant clusters by means of interconsonantal relations: Leftward Interonset Government (LIO) and Rightward Interonset Government (RIO). A regular introduction to all theoretical tools used in the analysis ensues in Section 4. It will be argued that this new combined model allows us to account for the distribution of vocalic quantity in Icelandic in a more efficient way than other variants of CVCV. We will also put forward a new interface operation: upgrading of Final Empty Nuclei (FEN), which takes place at Vocabulary Insertion.

\section{Basic facts}

Icelandic is a language with tonic lengthening. All stressed vowels in open syllables are long, whereas all remaining vowels are short. Vowel length is non-contrastive and fully predictable from the phonological context. The literature therefore takes for granted that lengthening is inextricably connected with syllabification.

However, the precise definition of the aforementioned open syllable is far from trivial and to some extent incompatible with how the term is commonly understood. According to Árnason $(1998,2011)$ there are two syllabification algorithms: lexical and post-lexical. The lexical syllabification algorithm operates in monomorphemic words, in words with inflectional endings, and in class 1 derivatives. ${ }^{1}$ The post-lexical algorithm is active in class 2 derivatives, in compounds, and across word boundaries. ${ }^{2}$ The application of each algorithm

1 The terms class I and class II are used only descriptively in this paper and they should not be interpreted as indicating the commitment of the author to the theory of Lexical Phonology. The same applies to the diacritics + and \# which are also intended to do nothing more than to express symbolically the relative "closeness" of two concatenated morphemes - the symbol + indicates class 1 or an inflectional morpheme boundary, whereas \# indicates class 2, a compound-internal boundary, or a postlexical context.

2 This is quite an unexpected division, since inflectional endings typically behave as though they were placed farther from the root than class 1 or even class 2 affixes. However, within the 
causes a different distribution of vocalic quantity on the surface. The main difference between the two algorithms lies in the way they parse clusters containing the least sonorous Icelandic segments, $/ \mathrm{p}^{\mathrm{h}}, \mathrm{t}^{\mathrm{h}}, \mathrm{k}^{\mathrm{h}}, \mathrm{s} /$.

\subsection{Lexical syllabification}

The 'lexical' rule generates long vowels in the following inventory of environments:

(1) a. the stressed vowel in a monosyllabic word, e.g. bú [pu:] 'farm, nom.sg.'

b. the stressed vowel before a vowel, e.g. búa ['pura] 'to live'

c. the stressed vowel before a CV sequence, e.g. taka ['t $\left.{ }^{\mathrm{h}} \mathrm{a}: \mathrm{k}^{\mathrm{h}} \mathrm{a}\right]$ 'to take'

d. the stressed vowel before a branching onset (the ptks+jvr rule), e.g. nepja ['nع:p ${ }^{\mathrm{h}}$ ja] 'cold weather, nom.sg.', götva ['kœ:t ${ }^{\mathrm{h}} \mathrm{va}$ ] 'to discover', sötra ['sœ: $t^{\mathrm{h}} \mathrm{ra}$ ] 'to slurp'

e. the stressed vowel in a monosyllabic (s)(C)(C)VC word, e.g. pak [ $\left.\theta \mathrm{a}: \mathrm{k}^{\mathrm{h}}\right]$ 'roof, nom.sg.', hús [hu:s] 'house, nom.sg.', vor [vo:r] 'spring, nom.sg.'

The first three cases (a-c) can be dubbed uncontroversial and would be classified as open syllables by virtually any phonologist. The syllable boundary is placed after the stressed vowel (bú.a, ta.ka), as there is no consonant which could be syllabified as a coda.

There is also a set of consonant clusters which do not block lengthening when they happen to come after the stressed nucleus. These are assumed to form branching onsets. The first member of such a cluster must be one of the four least sonorous segments $/ \mathrm{p}^{\mathrm{h}}, \mathrm{t}^{\mathrm{h}}, \mathrm{k}^{\mathrm{h}}, \mathrm{s} /$, and the second member one of the three most sonorous segments $/ \mathrm{j}, \mathrm{v}, \mathrm{r} / .^{3}$

On top of that, the word-final consonant is assumed to be extrametrical, since monosyllabic words with a single consonant at the right edge always display a long vowel.

In all other cases the vowel is short. This applies to the stressed vowel before all clusters different from the ones mentioned in (d), and to all unstressed vowels. Examples include hestur ['hestyr] 'horse, nom.sg.', senda ['senta] 'to

limits of this paper we will not attempt to explore the issue of why respective groups of Icelandic morphemes pattern in the way they do. This issue is left for future research.

3 Icelandic /v/ is typically classified as a sonorant, the evidence being of both phonological and phonetic nature. For discussion see Botma (2008), Árnason (2011: 106-107). 
send', orga ['orka] 'to yell', emja ['عmja] 'to wail'. The vowel is also short when a cluster arises after concatenation of a class I affix, e.g. hag+naður ['haknaðyr] 'profit, nom.sg.'

\subsection{Post-lexical syllabification}

When other chunks are concatenated, the lexical syllabification algorithm is replaced by the post-lexical algorithm. The main difference between them lies in the way in which clusters involving the four segments $/ \mathrm{p}^{\mathrm{h}}, \mathrm{t}^{\mathrm{h}}, \mathrm{k}^{\mathrm{h}}, \mathrm{s} /$ are parsed. In post-lexical contexts, a long vowel is found in all cases in which the monosyllabic stem ends in $/ \mathrm{p}^{\mathrm{h}}, \mathrm{t}^{\mathrm{h}}, \mathrm{k}^{\mathrm{h}}, \mathrm{s} /$, no matter what morpheme is concatenated to its right.

Let us start with providing a representative sample of examples in which this type of syllabification is reported to apply: compounds, derivatives with a class II affix, and cross-word sequences.

(2) a. compounds with the first member of the (s)(C)(C)VC type V:C V̌C\#C haf [ha:v] 'ocean, nom.sg.' haf\#kola ['havkola] 'sea breeze, nom.sg.' rauð [rœy:ð] 'red, nom.sg.fem.' rauð\#vín ['rœyðvin] 'red wine, nom.sg.' vor [vo:r] 'spring, nom.sg.' vor\#kuldi ['vorkyltt] 'spring chill, nom.sg.'

b. class II derivatives with the root of the $(\mathrm{s})(\mathrm{C})(\mathrm{C}) \mathrm{VC}$ type

$\mathrm{V}: \mathrm{C}$

âr [aurr] 'year, nom.sg.' ár\#legur ['aurlcyrr] 'annual, nom.sg.masc.' dag [ta:y] 'day, acc. sg.' dag\#legur ['tayleyrr] 'daily, nom.sg.masc.' fin [fi:n] 'elegant, nom.sg. fin\#legur ['finleyrr] 'delicate, nom.sg. fem.' masc.'

lof [lo:v] 'praise, nom.sg.' lof\#legur ['lovleyrr]'praiseworthy, nom.sg. masc.'

rauð [rœy:ð] 'red, nom.sg. rauð\#leitur ['rœyðlcit ${ }^{\mathrm{h}} \mathrm{yr}$ ] 'reddish, nom.sg. fem.' masc.'

c. compounds with the first root of the $(\mathrm{s})(\mathrm{C})(\mathrm{C}) \mathrm{VT}$ type

$\mathrm{V}: \mathrm{T}$

$\mathrm{V}: \mathrm{T} \# \mathrm{C}$

bak [pa:k $\left.{ }^{\mathrm{h}}\right]$ 'back, nom.sg.' bak\#poki ['pa:k $\left.{ }^{\mathrm{h}} \mathrm{p}^{\mathrm{h}} \mathrm{c}^{\mathrm{h}} \mathrm{i}\right]$ 'rucksack, nom.sg.' djúp [tju:p ${ }^{\mathrm{h}}$ ] 'depth, nom. djúp\#skyggn ['tju:p'skikn] 'profound, nom. sg.' $\quad$ sg.masc.'

haus [hœy:s] 'head, nom.sg.' haus\#tak ['hœy:st ${ }^{\mathrm{h}} \mathrm{ak}^{\mathrm{h}}$ ] 'head-lock, nom.sg.' 
hvít [ $\left[\mathrm{k}^{\mathrm{h}} \mathrm{vi}: \mathrm{t}^{\mathrm{h}}\right]$ 'white, nom. hvít\#vín [' $\left.\mathrm{k}^{\mathrm{h}} \mathrm{vi}: \mathrm{t}^{\mathrm{h}} \mathrm{vin}\right]$ 'white wine, nom.sg.' sg.fem.'

d. class II derivatives with the root of the $(\mathrm{s})(\mathrm{C})(\mathrm{C}) \mathrm{VT}$ type

V:T V:T\#C

bros [pro:s] 'smile, nom.sg.' bros\#leitur ['pro:slcit $\left.{ }^{\mathrm{h}} \mathrm{Yr}\right]$ 'smiling, nom.sg.masc.'

hvít [ $\left[\mathrm{k}^{\mathrm{h}} \mathrm{vi}: \mathrm{t}^{\mathrm{h}}\right]$ 'white, nom.sg.fem.' hvít\#leitur [' $\left.\mathrm{k}^{\mathrm{h}} \mathrm{vi}^{\mathrm{h}} \mathrm{t}^{\mathrm{h}} \mathrm{l} \mathrm{cit}^{\mathrm{h}} \mathrm{yr}\right]$ 'whitish, nom.sg.masc.'

sjúk [sju:k'] 'sick, nom.sg.fem.' sjúk\#legur ['sju:k'leyrr] 'sickly, nom. sg.masc.'

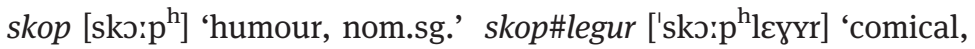
nom.sg.masc.'

e. compounds with a /h/-initial second member

$\mathrm{V}: \mathrm{C}$

$\mathrm{V}: \mathrm{C} \# \mathrm{~h}$

bað [pa:ð] 'bath, nom.sg.'

bað\#herbergi ['pa:ðherperci] 'bathroom, nom.sg.'

draum [trœy:m] 'dream, acc.sg.' draum\#heimur ['trœy:mheimyr] 'dreamworld, nom.sg.'

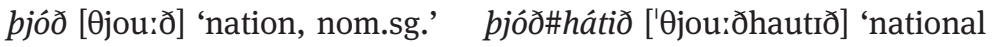
holiday, nom.sg.'

f. compounds with a vowel-initial second member

$\mathrm{V}: \mathrm{C} \quad \mathrm{V}: \mathrm{C} \# \mathrm{~V}$

blóð [plou:ð] 'blood, nom. blóð\#æði ['plou:ðaiðı] 'vein, nom.sg.' sg.' blóð\#eitrun ['plou:ðcitryn] 'blood poisoning, nom.sg.'

vor [vว:r] 'spring, nom.sg.' vor\#annir ['vo:rannır] 'spring field works, nom.pl.'

g. words of the $(\mathrm{s})(\mathrm{C})(\mathrm{C}) \mathrm{VC}$ type in postlexical cohesion $\mathrm{V}: \mathrm{C}$

Ég kom heim [hci:m]

I came home

'I came home.'

V̌C\#C

Ég kom heim til hans [...hrim'trlans]

I came home to him

'I came to his house.' 
h. words of the $(\mathrm{s})(\mathrm{C})(\mathrm{C}) \mathrm{VT}$ type in postlexical cohesion

$\mathrm{V}: \mathrm{T}$

Ég tók mat [ma:t ${ }^{\mathrm{h}}$ ]

I took food

'I took food.'

V:T\#C

Ég tók mat með mér [ma: $\mathrm{t}^{\mathrm{h}} \mathrm{m \varepsilon ðmj \varepsilon r]}$

I took food with me

'I brought along some food.'

The first member of every item depicted in the right-hand column of $(2 a-f)$ is a monosyllabic (s)(C)(C)VC stem. The second member is either another stem or a class II affix. The quantity of the stressed vowel of each derivative is not constant, however. It is clearly dependent on the final consonant of the first member and/or on the left edge of the second member.

When the final consonant of the first member is a sonorant or a nonsibilant) fricative, and the second member begins with any consonant different from $/ \mathrm{h} /$, then the vowel of the complex word is always short, as seen in (2ab). When the first member ends in one of the four segments $/ \mathrm{p}^{\mathrm{h}}, \mathrm{t}^{\mathrm{h}}, \mathrm{k}^{\mathrm{h}}, \mathrm{s} /$, then the stressed vowel of the derivative always ends up long, as can be seen in (2bc). It does not matter what is concatenated - the melody of the second member does not play any role. It may be a sonorant (sjúk\#legur 'sickly, nom.sg.masc.'), another fortis plosive (bak\#poki 'rucksack, nom.sg.'), or even a cluster (djúp\#skyggn 'profound, nom.sg.masc.'). Examples listed in (2e) and (2f) contribute even more to the complexity of the pattern: when the second member begins with $/ \mathrm{h} /$, then the final consonant of the first member is irrelevant and the output always displays lengthening. The same happens when the second member is vowel-initial (although this should not come as a surprise, since the last consonant of the first member can be simply interpreted as being resyllabified as an onset in these examples). Data included in ( $2 \mathrm{~g})$ and (2h) show that the situation characterising compounds and class II derivatives is also observed across words.

The pattern is very problematic for any framework assuming only a simple syllabification algorithm, which can parse a word-internal consonant cluster either as a branching onset, or as a coda-onset cluster. Clusters arising in (2b) could be assumed to be branching onsets without objections only if the second member is one of the weakest segments /j, v, r/, for instance in hvít\#vín ['k $\left.\mathrm{k}^{\mathrm{h}} \mathrm{vi} \mathrm{t}^{\mathrm{h}} \mathrm{vin}\right]$ 'white wine, nom.sg.'. But this is not the case: lengthening takes place also when the second member begins with a consonant different than the 
three mentioned above. Most clusters in (2b), like $/ \mathrm{sl} /$ or $/ \mathrm{t}^{\mathrm{h}} \mathrm{l} /$, always block lengthening morpheme-internally. For instance, underlying /vcisla/ veisla 'party, nom.sg.' surfaces as ['veisla], and underlying /ait ${ }^{\mathrm{h}} \mathrm{la} /$ ætla 'to intend' as ['aihtla] (with short diphthongs in both cases; also with preaspiration in the latter case). This fact is crucial evidence for the fact that they cannot be branching onsets. So, can these sequences be coda-onset clusters? As a matter of fact, they cannot, because we would expect a short vowel to surface to their left. Also, Icelandic displays rich lenition phenomena in the internal coda position, like spirantisation of plosives. We could expect underlying $/ \mathrm{k}^{\mathrm{h}} \mathrm{p}^{\mathrm{h}} /$ in bak\#poki ['pa:k $\mathrm{k}^{\mathrm{h}} \mathrm{p}^{\mathrm{h}} \mathrm{c}^{\mathrm{h}} \mathrm{i}$ ] 'rucksack, nom.sg.' to surface as [xp]. Also, $/ \mathrm{t}^{\mathrm{h}} \mathrm{l}$ in hvít\#leitur [' $\mathrm{h}^{\mathrm{h}} \mathrm{vi} \cdot \mathrm{t}^{\mathrm{h}}$ leit ${ }^{\mathrm{h}} \mathrm{yr}$ ] 'whitish, nom.sg.masc.' would display preaspiration, giving rise to [htl], along the lines of the aforementioned ætla 'to intend'.

A natural solution may seem to blame the domain structure for the observed effects: all items listed in (2ab) are single domains, while all remaining items involve multiple domains. However, such a statement is far from constituting a solution on its own, at least due to the fact that often the same affixes (like leitur and-legur) produce disparate effects in different lexical items (cf. the short vowel in rauð\#leitur ['rœyðleit ${ }^{\mathrm{h}} \mathrm{Yr}$ ] 'reddish, nom.sg.masc.' vs. the long vowel in hvít\#leitur [' $\mathrm{k}^{\mathrm{h}} \mathrm{vi}: \mathrm{t}^{\mathrm{h}}$ leit ${ }^{\mathrm{h}} \mathrm{yr}$ ] 'whitish, nom.sg.masc.'). Why should these affixes be separate domains in some cases, but not in others? Domainhood should be a consistent property of every affix under consideration and should not be subject to lexical variation.

There should also be no observable correlation between domain structure and the presence of some phonological feature. Unfortunately, this is exactly what the Icelandic data force us to state: when the final consonant of the first member of a compound (or a class II derivative) is $/ \mathrm{p}^{\mathrm{h}}, \mathrm{t}^{\mathrm{h}}, \mathrm{k}^{\mathrm{h}}, \mathrm{s} /$, then the whole complex word appears to contain two phonological domains. Otherwise, it contains just one domain. Nonetheless, there appears to be a consensus on the claim that domain structure reflects morpho-syntactic derivation - domains are directly provided by morpho-syntax (e.g. Kaye 1995). In light of this fact, melodic conditioning for domain resolution would be a very odd phenomenon, which no phonologist would like to endorse. It would suggest that phonology can do more than just parse strings sent into it by the spell-out mechanism - it can influence spell-out on its own. Postulating melodically conditioned morphological structure would be a blatant violation of modularity and would have massive consequences for the architecture of grammar.

In this paper it will be attempted to formulate an analysis fully compliant with modularity (Fodor 1983). Even though the modular take is not embraced by the whole generative community (see e.g. Pak 2008; Samuels 2009 for recent non-modular approaches to phonology-morphosyntax interface), we assume 
modularity to be the cornerstone of the generative model of language and to follow directly from the innateness of language faculty (see Scheer [2011: 497-561] for a very well-articulated introduction to modularity for linguists). We espouse the traditional architecture of grammar based upon the inverted T model (Chomsky 1965), in which phonology is only an interpretational device. A possibility of spell-out being influenced by the melodic structure of terminals or of phonological computation directly referring to morphosyntactic structure must be explicitly rejected in such an environment.

\section{Existing accounts}

On the following pages we will briefly review the few extant approaches to the problem, pointing out their advantages and disadvantages. Anomalous phonological behaviour of compounds was noticed as early as in Guðfinnsson (1946: 71), and Einarsson (1945: 6), but the first theoretical analysis of the problem was Gussmann (1985).

We will start our overview with Gussmann's (1985) early proposal and Booij's reaction to it. Afterwards, we will take a look at Árnason's (1998) explanation couched in Optimality Theory and Gussmann's second attempt, this time within the framework of Standard Government Phonology (2002).

\subsection{Gussmann (1985) and Booij (1986)}

Gussmann's pioneering (1985) contribution was couched in linear SPE, in which morphosyntactic information was represented by segment-like diacritics: /\#/ for the word boundary and $/+/$ for the morpheme boundary. Gussmann did not recognize the significance of syllabic divisions, proposing a rule of lengthening defined in segmental terms (1985: 77):

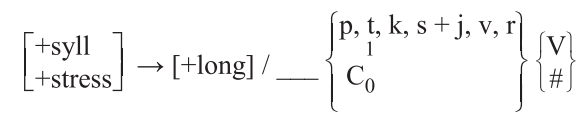

As regards compounds and class II derivatives, Gussmann's point of departure was assigning the strong /\#/ boundary to all of them. Since /\#/ was included in the environment of the rule, this was enough to ensure that derivatives of the (2cd) type undergo lengthening no matter what follows the first member. But 
how can the data from ( $2 \mathrm{ab}$ ) be explained in such a case? In order to answer this question, Gussmann formulates a rule of boundary weakening (1985: 90):

$$
\# \rightarrow+/\left[\begin{array}{l}
+\mathrm{V} \\
+ \text { stress }
\end{array}\right]\left[\begin{array}{l}
+ \text { conson } \\
+ \text { voice }
\end{array}\right]
$$

The rule transforms the word boundary into a morpheme boundary in the environment of a stressed vowel followed by a voiced consonant, i.e. every consonant different than $/ \mathrm{p}^{\mathrm{h}}, \mathrm{t}^{\mathrm{h}}, \mathrm{k}^{\mathrm{h}}, \mathrm{s} /$. Ordering this rule before the lengthening rule ensures the proper output for the derivatives in (2ab) too. That is, boundary weakening bleeds lengthening.

It does not take much to discern that the rule is entirely arbitrary. It is impossible to identify a rationale for the boundary to be weakened in exactly this particular environment. The correlation between voice and /\#/ or $/+/$ is entirely unclear.

Gussmann's rule was reformulated by Booij (1986) within the framework of Prosodic Phonology, in which no diacritic segment-like boundaries were granted existence. Booij (1986: 14) proposes a rule which unifies two domains into one, operating on the Prosodic Word level:

$$
\left(\ldots\left[\begin{array}{l}
+\mathrm{V} \\
+ \text { stress }
\end{array}\right]\left[\begin{array}{l}
+ \text { cons } \\
+ \text { voice }
\end{array}\right]\right)_{\omega}(\ldots)_{\omega} \rightarrow\left(\ldots\left[\begin{array}{l}
+\mathrm{V} \\
+ \text { stress }
\end{array}\right]\left[\begin{array}{l}
+ \text { cons } \\
+ \text { voice }
\end{array}\right] \ldots\right)
$$

Booij's rule is not less arbitrary than Gussmann's. The logical connection between the environment and the process of $\omega$-fusion is still missing.

The biggest disadvantage of both accounts is that they allow for manipulation of morpho-syntactic information by melodic properties of segments. This aspect is at odds with the modular interface theory, as stated in 1.2.

\section{2 Árnason (1998)}

Árnason (1998) makes an attempt to account for the differences in the distribution of vowel length at the lexical and postlexical level by means of syllabification only. No notions such as "domains" or "boundaries" are used. Instead, he espouses the existence of the Lexical Phonology-type Level I and Level II and argues that each of them has a different rule of syllabification. Árnason's framework is a variant of Stratal Optimality Theory (Kiparsky 1998; Bermúdez-Otero 2011).

Árnason employs in his analysis the strength scale for consonants that is used for Icelandic at least since Vennemann 1972. He classifies $/ \mathrm{p}^{\mathrm{h}}, \mathrm{t}^{\mathrm{h}}, \mathrm{k}^{\mathrm{h}}, \mathrm{s} /$ as 
the strongest segments, and /j, v, r/ as the weakest ones (1998: 17). He also formulates constraints which make direct reference to the scale. The full rankings provided by Árnason will not be reproduced here due to their lack of relevance for the discussion - only the ONSET constraints will be examined.

At the lexical level, there is a constraint “ONSET (LEXICAL): p, t, k, s beat j, v, r", which captures the ptks+jvr rule and generates proper syllabification patterns when unranked with constraints NoCodA and FillNucleus. The ranking for the postlexical level looks the same, but a different onset constraint is active: "ONSET (POSTLEXICAL): $\mathrm{p}, \mathrm{t}, \mathrm{k}, \mathrm{s}$ beat all”. Thanks to this constraint the fortis plosives and /s/ are postlexically strong enough to build onsets with any kind of consonant.

In other words, Árnason's account boils down to syllabifying all $/ \mathrm{p}^{\mathrm{h}}, \mathrm{t}^{\mathrm{h}}$, $\mathrm{k}^{\mathrm{h}}, \mathrm{s}$-initial clusters in compounds as branching onsets, regardless of the sonority slope. This often applies to sequences of two aspirated plosives (like $/ \mathrm{k}^{\mathrm{h}} \mathrm{p}^{\mathrm{h}} /$ in bakpoki 'rucksack, nom.sg.') or to sequences of more than two consonants (like [ $\mathrm{k}^{\mathrm{h}} \mathrm{sv}$ ] in bak\#svipur 'look from the back, nom.sg.' or [p ${ }^{\mathrm{h}} \mathrm{sk}$ ] in djúp\#skyggn 'profound, nom.sg.masc.'). This analysis is a patent violation of sonority sequencing and opens the door to the consideration of anything and its reverse as a branching onset, which means that the syllabic notion is completely detached from its melodic basis. This is not desirable for phonological theory, since the generalizations about branching onsets are pervasive cross-linguistically. Árnason's approach seems to be impressionistic and circular: a branching onset is any consonant sequence to the left of which long vowels occur. No further criteria are provided, and no consequences of such a decision are taken into account.

\subsection{Gussmann (2002)}

Gussmann (2002) is a purely representational account, formulated within the theory of Standard Government Phonology (SGP) and, similarly to Árnason (1998), based only on syllabification and with no explicit reference to morphosyntactic information in the form of boundaries or domains.

Gussmann's (2002) analysis involves a syllabification algorithm which makes use of empty nuclei. This means that a sequence of two word-internal consonants can be parsed not only as a branching onset or coda-onset cluster, but also as a bogus cluster enclosing an empty nucleus. Recognising bogus clusters opens new possibilities and enables him to avoid some problems, for example pertaining to sonority slopes in branching onsets. In this respect SGP fares better than syllabification algorithms with just two types of word-internal clusters. 
The generalization which holds for the Icelandic system and that Gussmann (2002) relies on can be summarised in two simple statements:

- Stressed rhymes always need to branch.

- Aspirated plosives can never be syllabified in a coda.

In other words, when the syllabification algorithm comes across a fortis aspirated plosive, it places it in the onset position. This automatically brings about branching of the preceding nucleus and a long vowel on the surface.

This regularity is assumed by Gussmann to hold for both simplex and complex words:

"Within the syllabic approach we need to say nothing in addition to what has already been established, namely that fortis plosives can only appear in the onset. When this principle is followed, it is obvious that the preceding syllable is open and its nucleus has to branch. No separate generalisations for simplex and complex words are necessary.” (Gussmann 2002:183)

Let us take a look at two representations compatible with Gussmann's proposal. The words chosen for exposition are rauð\#leitur ['rœyðlcit ${ }^{\mathrm{h}} \mathrm{yr}$ ] 'reddish, nom.sg. masc.' and hvít\#leitur ['k $\mathrm{k}^{\mathrm{h}} \mathrm{vi} \cdot \mathrm{t}^{\mathrm{h}} \mathrm{l}_{\text {cit }}{ }^{\mathrm{h}} \mathrm{yr}$ ] 'whitish nom.sg.masc.' (Figures 1 and 2).

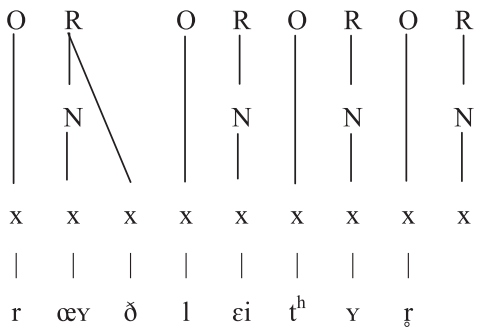

Figure 1: rauð\#leitur 'reddish, nom.sg.masc.' in SGP.

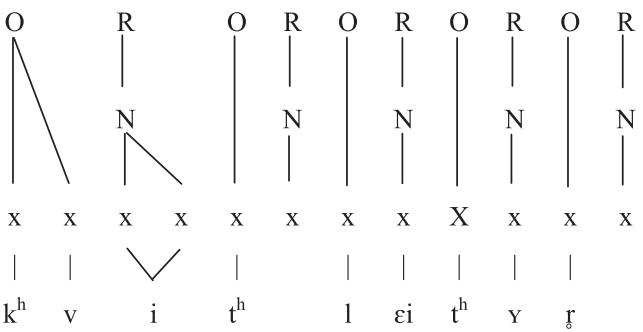

Figure 2: hvít\#leitur 'whitish, nom.sg. masc.' in SGP.

The dental fricative [ð] can be syllabified as a coda without reservation. It is incorporated into the branching rhyme as its complement, preventing the nucleus from branching (SGP does not allow rhymes dominating more than two skeletal positions). Therefore a short vowel appears on the surface. 
In contrast, Icelandic $\left[\mathrm{t}^{\mathrm{h}}\right]$ can never be syllabified as a coda in Gussmann's analysis. It is thus destined to occupy its own onset position, which (in line with the requirements of the theory) needs to be followed by an empty nucleus. Since the preceding rhyme does not have a complement, it needs to satisfy the requirement of branching somewhere else: on the level of the nucleus.

The unquestionable advantage of Gussmann's proposal is its inherent simplicity - it succeeds in unifying the apparently different lexical and postlexical algorithms in just one. When it is assumed that "empty nuclei are one of the mechanisms available for ensuring the proper syllabification of words in a language" (2002: 184), we are no longer forced to view problematic consonantal sequences (like $/ \mathrm{t}^{\mathrm{h}} \mathrm{l} /$ or $/ \mathrm{p}^{\mathrm{h}} \mathrm{k}^{\mathrm{h}} /$ ) as branching onsets. We also do not need to resort to any kind of extraphonological information.

However, there are several important factors which beg the question when assuming this kind of syllabification algorithm. Note that Gussmann operates on only one level of representation. Within such a model, it is not entirely clear how productive alternations can be handled. Icelandic fortis plosives are believed to participate in various phonological processes, like preaspiration and spirantisation. When this happens, they are not realised as fortis plosives anymore. Consider the following data:

a. Preaspiration

hvít $/ \mathrm{k}^{\mathrm{h}}$ vit $\mathrm{h} / \rightarrow$ [k $\mathrm{k}^{\mathrm{h}}$ vi: $\left.\mathrm{t}^{\mathrm{h}}\right]$ 'white, nom.sg.fem.'

hvitt $/ \mathrm{k}^{\mathrm{h}} \mathrm{vit}^{\mathrm{h}}+\mathrm{t}^{\mathrm{h}} / \rightarrow$ [k $\mathrm{k}^{\mathrm{h}}$ viht] 'white, nom.sg.neut.'

ætla /ait ${ }^{\mathrm{h}} \mathrm{l}+\mathrm{a} / \rightarrow$ ['aihtla] 'to intend'

b. Spirantisation

vaka $/$ vak $^{\mathrm{h}}+\mathrm{a} / \rightarrow$ ['va:k $\mathrm{k}^{\mathrm{h}} \mathrm{a}$ 'to be awake'

vakti $/$ vak $^{\mathrm{h}}+\mathrm{t}^{\mathrm{h}} \mathrm{I} / \rightarrow$ ['vaxtI] 'I was awake'

ríkur /rik ${ }^{\mathrm{h}}+\mathrm{yr} / \rightarrow$ ['ri:k ${ }^{\mathrm{h}} \mathrm{yr}$ ] 'rich, nom.sg.masc.'

ríks /rik ${ }^{\mathrm{h}}+\mathrm{s} / \rightarrow$ [rixs] 'rich, gen.sg.masc.'

As can be easily inferred, the same sequences of underlying consonants behave differently morpheme-internally (and across the weak / / boundary) than in compounds. For instance, the underlying sequence $/ \mathrm{Vt}^{\mathrm{h}} \mathrm{l} /$ surfaces as [Vhtl] (with preaspiration and without lengthening, like in ætla 'intend'). In contrast, when the two consonants belong to two different members of a compound, i.e. the underlying structure is $/ \mathrm{Vt}^{\mathrm{h}} \# \mathrm{l} /$, then the phonetic output is [V: $\mathrm{t}^{\mathrm{h}} \mathrm{l}$, like in the quoted example of hvít\#leitur 'whitish, nom.sg.masc.'. If Gussmann's syllabification algorithm operated blindly, it would not distinguish between ætla and hvit\#leitur, returning the same output in both cases. This is why ætla would 
have to be individually stored and postulated not to have anything to do with the (underlying) aspirated $/ \mathrm{t}^{\mathrm{h}} /$. Consequently, also a form like hvitt [ $\mathrm{k}^{\mathrm{h}} \mathrm{viht}$ ] 'white, nom.sg.neut.' needs to be assumed to be separately stored in the lexicon and synchronically unrelated to hvit [ $\left[\mathrm{k}^{\mathrm{h}}\right.$ vi: $\left.\mathrm{t}^{\mathrm{h}}\right]$ 'white, nom.sg.fem.' The rule of spirantisation which turns $/ \mathrm{k}^{\mathrm{h}}$ / into $/ \mathrm{x} /$ before a non-homorganic plosive leads to complications of the same kind, since the infinitive form vaka ['va: $\mathrm{k}^{\mathrm{h}} \mathrm{a}$ ] 'to be awake' and the preterite vakti ['vaxtI] 'I was awake' also must be separate lexical entries. This approach drastically expands the lexicon and storage and reduces computation to the bare minimum (see the criticism in Scheer 2012b; Fortuna 2013).

It is probably a surface-true generalization that fortis plosives appear only in the onset position. This could be formulated on the basis of the analysis of the syllabification of the existing forms and paradigms, but there is one important thing missing here. Language is a productive system and all of the aforementioned regularities apply also to novel formations. Every new compound with the first member being of the $(\mathrm{s})(\mathrm{C})(\mathrm{C}) \mathrm{VT}$ type will display a long vowel and a faithfully surfacing plosive (as in bak\#poki ['pa: $\mathrm{k}^{\mathrm{h}} \mathrm{p}^{\mathrm{h}} \mathrm{\jmath c}{ }^{\mathrm{h}} \mathrm{i}$ ] 'rucksack, nom.sg.'). Simultaneously, any (s)(C)(C)VT stem followed by a consonant-initial inflectional ending (like the -ti) will surface with a short nucleus and a lenited (spirantised/preaspirated) plosive (as in vakti ['vaxtI] 'I was awake'). This observation is valid even for nonce words. If morphosyntactic divisions are entirely irrelevant and everything is attributable to the syllabification algorithm, how do native speakers know which of the rules should be applied? In Gussmann's account there is no reason why the preterite of $v a k a$ ['va: $\mathrm{k}^{\mathrm{h}} \mathrm{a}$ ] 'to be awake' cannot be $\left.\star^{[}{ }^{\prime} v a: k^{h} \mathrm{t}^{\mathrm{I}} \mathrm{I}\right]$. It could certainly be the case that this particular verb happens to have an allomorph with a short vowel, ['vaxtr], but this assumption does not explain why every verb (existing or not) with a monosyllabic stem and a fortis plosive at the right edge behaves in this way.

The last flaw in Gussmann's proposal concerns the syllabification of /s/. He assumes this segment to be a double agent, which sometimes syllabifies as an onset, and sometimes as a coda (2002: 191-192). The quoted examples are veisla ['veisla] 'party, nom.sg.' and bros\#legur ['pro:sleyrr] 'smiling, nom.sg.masc.'. Gussmann categorically rejects the explanation based on differing domain structure, claiming that the suffix -legur cannot be a domain on its own, since compounds like dag\#legur ['tayleyrr] 'daily, nom.sg.masc.' or lof\#legur ['lovleyrr] 'praiseworthy, nom.sg.masc.' always display a short vowel (2002: 190-191). Like in the case of fortis plosives, for Gussmann the only reason for the difference in vowel length is syllabification. Disappointingly, the precise factors which are responsible for the syllabification of /s/ remain mysterious. Consider what Gussmann says about /s/: 
The question suggests itself as to what enforces the two different syllabifications of what is obviously the same phonetic segment. This is a question we cannot go into here, as we would need to determine precisely the properties responsible for the aspiration of plosives and the voicing of spirants. (...) Crucially, then, the Icelandic [s] is ambiguous in the phonological effects that it is accompanied by. Since phonological effects are not metaphysical phenomena but are produced by specific properties, we can only surmise that the Icelandic [s] is a double agent: in some words it displays properties which are not present in others. What these properties are can be established by a detailed study of the language in question. Our aim here has merely been to demonstrate the existence of the phonological diversity behind phonetic identity. (Gussmann 2002: 192-193)

After reading this the reader may know everything but the criteria for the syllabification of /s/. Even though Gussmann tries to link the process with the patterning of aspirated plosives and voiced fricatives, no clear proposal is made. Thus one may get the impression that it is entirely arbitrary whether a given word with /s/ will syllabify this segment as a coda or as an onset. In a recent contribution, Czarnecki (2013: 96-97) tries to develop Gussmann's proposal by stating that the /s/ syllabified in the onset contains the $\{\mathrm{H}\}$ element, whereas the /s/ syllabified in the coda lacks this prime. ${ }^{4}$ That is, there are two independent phonological expressions, differing in their elemental make-up, but with the same phonetic correlate. But this proposal does not solve the problem.

First of all, sometimes the $/ \mathrm{s} /$ belonging to one and the same morpheme may be syllabified as an onset or as a coda, e.g. brosa ['pro:sa] 'to smile' vs. brosti ['prostr] 'I smiled'. If the /s/ is not the same in both forms, then the infinitive and the past tense cannot be phonologically related and this difference also needs to be the domain of allomorphy - which is consistent with Gussmann's view that alternants with a long and short vowel need to have separate representations. Hence, the infinitive would be stored with a long vowel and the $\{\mathrm{H}\}$-ful $/ \mathrm{s} /$, whereas the past tense form with a short vowel and the $\{\mathrm{H}\}$-less $/ \mathrm{s} /$. This solution could be called a prototypical example of "allomorphy abuse".

Second, the general pattern of the syllabification of /s/ is obvious and selfimposing when morphosyntactic information is taken into account. There is no need to recognise two phonological entities pronounced as [s]. The 'syllabification' of /s/ in word-internal clusters runs along the following lines: morphemeinternally and across a 'weak' boundary it is syllabified as a coda (as evidenced by a short vowel in veisla 'party, nom.sg.', taska 'bag, nom.sg.', and bros $+t i$

4 The element $\{\mathrm{H}\}$ corresponds to the feature [spread glottis] in more traditional phonological vocabulary. For an introduction to the Element Theory see e.g. Harris (1994), Cyran (2010), and Backley (2011). Within the present paper we refrain from using the Element Theory, even though it appears to constitute the default view of subsegmental structure for virtually all variants of Government Phonology. 
'I smiled'), and before a strong boundary as an onset (like in bros\#legur 'smiling, nom.sg.masc.' and bros\#gjarn 'funny, nom.sg.masc.').

The lesson which Gussmann's second proposal teaches us is that the problem is hardly explicable when only syllabification is taken into account, without recourse to domain/boundary information. Recognising bogus clusters cannot account for the entire pattern. Morphosyntactic conditioning cannot be eluded, and overlooking this aspect leads to wrong predictions.

\section{Procedural vs. representational intervention and potential explanations}

Having established that the activity of the interface needs to be acknowledged is only the point of departure. The next decision which needs to be made is in what way and through what channel the interface bears on phonological computation in Icelandic. The interaction of the interface with syllabification needs to be explicitly described and explained. In this section it will be demonstrated that any attempt to explain the distribution of vocalic quantity with reference to only domain/boundary information is bound to fail. This is due to the mixed phonological/morphosyntactic conditioning of the phenomenon.

Morphosyntax can bear on phonology in two ways: procedurally and representationally. Procedural intervention is based upon the synergy of phonological computation with the mechanism of spell-out. Strings are subjected to phonological computation in a piecemeal fashion: interpretation takes place from the most embedded chunk to the least embedded one. They are traditionally called cycles in phonological literature and known as phases in current syntactic theory (Chomsky 2001). Successive rounds of computation leave ample traces in phonology in the form of opacity effects. Representational intervention consists in either building prosodic structure (e.g. Nespor and Vogel 1986) or inserting boundaries at morphosyntactic junctures (as in Chomsky and Halle 1968).

In the following section we will make an attempt to examine the consequences of both approaches when applied to the analysis of relevant Icelandic data.

\subsection{Procedural intervention}

The aim of this section is to briefly consider how much the procedural approach can contribute to the problem of the distribution of vocalic quantity in Icelandic complex words. It will be shown that in order to generate the attested pattern, 
we would need to make a modularity-violating assumption of domain structure being conditioned by the melodic structure of terminal nodes. This is why the problem cannot be solved by procedural means only. No particular implementation of the procedural model will be favoured in the following exposition instead, we will try to keep the discussion as theory-neutral as possible.

Let us briefly remind ourselves the conditions for lengthening at the word level (already fleshed out in Section 1.1.): all stressed vowels in open syllables are lengthened, whereby the word-final consonant is always extrasyllabic. This makes monosyllabic words with a single consonant at the right edge always surface with a long vowel. The basic assumption for plurimorphemic words could be formulated as follows: the rule of lengthening applies after class I affixation but before class II affixation. Many procedural theories make also use of the so-called no-look-back devices, which ensure that already computed domains are 'frozen' for further computation. This system makes the following prediction:

- concatenation of a class I consonant-initial suffix should block lengthening; the consonant cluster arising on the boundary should be parsed as a codaonset cluster (except in case the resulting cluster is one of the permissible internal branching onsets in Icelandic, i.e. $/ \mathrm{p}^{\mathrm{h}}, \mathrm{t}^{\mathrm{h}}, \mathrm{k}^{\mathrm{h}}, \mathrm{s}+\mathrm{j}, \mathrm{v}, \mathrm{r} /$ )

- concatenation of a class II suffix should not influence the length of the base; phonological computation on the inner cycle should generate a long vowel; vowel length should be non-modifiable on a later cycle

Before we embark on the topic of compounds and class II derivatives, we will take a look at how class I affixation and inflection in Icelandic interacts with the distribution of vocalic quantity. Since the phenomena relevant for our considerations are observable only in monosyllabic (s)(C)(C)VC stems subsequently undergoing morphological extension, only such examples will be examined below. In the case of verbs, the imperative form was selected for exposition, since it is equivalent with the bare stem. The same is true of the nominative singular feminine form of adjectives.

a. the preterite endings ${ }^{5}$
gap ['ka:ph] 'gape, imp.'
gap + ti ['kaftr] 'I gaped'
heyr ['hei:r] 'hear, imp.'
$h e y r+\partial i$ ['heirðI] 'I heard'
hvíl ['k $\mathrm{h}$ vi:l] 'rest, imp.'
hvíl+di ['k $\left.\mathrm{k}^{\mathrm{h}} \mathrm{vilt \textrm {tI }}\right]$ 'I rested'

\footnotetext{
5 Icelandic has three weak preterite endings: - $-d i$, -ti, and - $\partial i$. Their distribution is assumed to be determined allomorphically. Since the precise shape of the ending has no bearing on the phenomenon of length, examples with all alternants are included.
} 
leyf ['lei:v] 'allow, imp.' leyf + [ ['leivðI] 'I allowed'

reis ['rci.s] 'raise, imp.' reis+ti ['rcistI] 'I raised'

b. $-t$ neuter ending

brýn [pri:n] 'urgent, nom.sg.fem.' brýn+t [print] 'urgent, nom.sg.

neut.'

gul [ky:l] 'yellow, nom.sg.fem.' gul $+t$ [kylt] 'yellow, nom.sg.neut.'

hvít [ $\left.\mathrm{k}^{\mathrm{h}} \mathrm{vi}^{\mathrm{t}} \mathrm{t}^{\mathrm{h}}\right]$ 'white, nom.sg.fem.' hvít $+t\left[\mathrm{k}^{\mathrm{h}}\right.$ viht] 'white, nom.sg.neut.'

tóm [ $\mathrm{t}^{\mathrm{h}}$ ou:m] 'empty, nom.sg.fem.' tóm $+t$ [ $\mathrm{t}^{\mathrm{h}}$ oumm] 'empty, nom.sg. neut.'

c. Class I suffix -lingur 'dim.'

bók [pou:k'] 'book, nom.sg.' bæk+lingur ['paihklınkrr] 'leaflet, nom.sg.'

grís [kri:s] 'pig, nom.sg.' grís+lingur ['krislınkrr] 'piglet, nom.sg.'

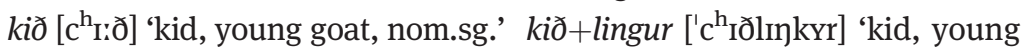
goat, nom.sg.'

The phenomena accompanying two inflectional endings (the verbal preterite ending $-d i /-t i /-ð i$ and the adjectival neuter nominative ending $-t$ ) and one derivational suffix (-lingur) presented in (7) fulfil the prediction of vowel shortness. When they are concatenated after a monosyllabic $(\mathrm{s})(\mathrm{C})(\mathrm{C}) \mathrm{VC}$ stem, the output never displays lengthening. The phonological behaviour is the same for class I derivatives and for simplex forms - compare e.g. the short nucleus of grís+lingur ['krislınkrr] 'piglet, nom.sg.' with beisli ['pcisli] 'bridle, nom.sg.'. In addition, the fortis plosives which are placed in the coda position undergo radical lenition: spirantisation $\left(/ \mathrm{p}^{\mathrm{h}} \mathrm{t}^{\mathrm{h}} / \rightarrow\right.$ [ft], e.g. gap $+t i$ ['kaftI] 'I gaped') and preaspiration (/ $\mathrm{t}^{\mathrm{h}} \mathrm{t}^{\mathrm{h}} / \rightarrow$ [ht], e.g. hvit $+t$ [ $\mathrm{k}^{\mathrm{h}}$ viht] 'white, nom.sg.neut.'). Exactly the same phenomena are observable when these clusters are intramorphemic, for instance september ['scftemper] 'September, nom.sg.', hatt ['haht] 'hat, acc. sg.' .

Unfortunately, derivatives of class II and compounds appear not to conform to the second prediction, i.e. to feature lengthening. They do so only under special circumstances: when the first member ends in $/ \mathrm{p}^{\mathrm{h}}, \mathrm{t}^{\mathrm{h}}, \mathrm{k}^{\mathrm{h}}, \mathrm{s} /$. Let us take a look at some forms:

a. Class II suffix -legur

bros [pross] 'smile, nom.sg.'

lof [lo:v] 'praise, nom.sg.' bros\#legur ['pro:sleyyr] 'smiling, nom.sg.masc.'

(!) lof\#legur ['lovleyrr] (*[o:]) 'praiseworthy, nom.sg.masc.' 
b. Class II suffix -leitur

hvít [ $\mathrm{k}^{\mathrm{h}}$ vi: $\left.\mathrm{t}^{\mathrm{h}}\right]$ 'white, nom.sg.fem.' hvít\#leitur [' $\mathrm{k}^{\mathrm{h}} \mathrm{vi} \cdot \mathrm{t}^{\mathrm{h}}$ leit $\left.{ }^{\mathrm{h}} \mathrm{Yr}\right]$ 'whitish, nom.sg.masc.'

rauð [rœy:ð] 'red, nom.sg.fem.'

(!) rauð\#leitur ['rœyðlcit ${ }^{\mathrm{h}} \mathrm{yr}$ ]

(^[œy:]) 'reddish, nom.sg.masc.'

c. Class II suffix -laus

hús [hu:s] 'house, nom.sg.'

hús\#laus ['hu:slœis] 'homeless, nom.sg.masc.'

von [vว:n] 'hope, nom.sg.'

(!) von\#laus ['vonlœis] (*[ว:])

'hopeless, nom.sg.masc.'

d. compounds

bak [pa:k $\mathrm{k}^{\mathrm{h}}$ 'back, nom.sg.'

bak\#poki ['pa:k $\left.{ }^{\mathrm{h}} \mathrm{p}^{\mathrm{h}} \mathrm{c}^{\mathrm{h}} \mathrm{i}\right]$ 'rucksack, nom.sg.'

vor [vว:r] 'spring, nom.sg.'

(!) vor\#kuldi ['vorkyltı] (*[ว:])

'spring chill, nom.sg.'

The words bros\#legur, hvít\#leitur, hús\#laus, and bak\#poki behave in line with expectations, but the underapplication of lengthening in the examples marked with the (!) is inexplicable under the assumptions of the procedural approach.

One could propose that the forms with (!) actually present class I concatenation - an option already mentioned in Section 1.2. This, however, would force us to recognize the influence of a melodic information on the spell-out mechanism. The generalisation would run as follows: if the final segment of the stem is $/ \mathrm{p}^{\mathrm{h}}, \mathrm{t}^{\mathrm{h}}, \mathrm{k}^{\mathrm{h}}, \mathrm{s} /$, then the affix belongs to class II (induces spell-out). If the final segment of the stem is any other segment, then the affix is class I (does not induce spell-out). In other words, spell-out is melodically conditioned. This conclusion is entirely incompatible with modularity and presupposes the architecture of grammar in which morphosyntactic computation has a direct access to the phonological structure of the terminals. The point of departure which we are adopting here is that the phonological domain structure is provided by morphosyntax and cannot be influenced by any melodic properties. Domains exist prior to phonological computation, or even prior to the insertion of phonological material (Late Insertion - Halle and Marantz 1994). In such architecture, melodically-conditioned domain structure does not have the right to exist.

In light of this fact, the mode of explanation based on procedural interface activity faces a big challenge. 


\subsection{Representational intervention and direct interface}

In mainstream phonology, representational intervention of the interface is manifest in two ways: either inserting boundary symbols (like /\#/ and /+/) or building prosodic constituency. Two examples of application of such representational items in the analysis of Icelandic postlexical syllabification (Gussmann 1985; Booij 1986) have already been reported upon in Section 2.1. It was argued that they were not successful due to the necessity of recognizing boundary mutation rules in order to return the desired output. This failure was caused by the mixed conditioning of the process. However, there is one more theory of representational intervention which may be exploited: Direct Interface (Scheer 2012a).

In the present section it will be argued that in its standard form, Direct Interface also fails to shed new light on the problem of postlexical syllabification in Icelandic. However, some benefits of the Direct Interface theory (more precisely, its CVCV implementation) will be evidenced, and some of its aspects will be used in the proposal which we will later issue in Section 4.

In Scheer's (2012a) view, conventional boundary symbols, like /\#/ and / /, are only diacritics and empty shells. The same is true for the currently most popular representational interface items, i.e. prosodic constituency. They do not belong to the vocabulary used in phonological computation in the absence of morphosyntactic divisions. Instead, Scheer develops the idea of Lowenstamm (1999) who proposed that word boundaries are translated into empty syllabic space (in the case of the CVCV theory: into an initial empty CV unit). Syllabic space is an inherently phonological object, which participates in phonological processing and immediately exerts influence on it ("Direct Effect", see Scheer 2012a: 117-121).

If a given boundary item is not inserted, we can expect non-impeded communication across the boundary, i.e. computation proceeds as if the morphosyntactic juncture were not there. In contrast, insertion of the boundary disrupts regular phonological computation. However, it is impossible that the same morphosyntactic item sometimes projects insertion of a representational object into the phonological string, and sometimes not. This is true for all theories of the interface: a given morphosyntactic structure has a stable phonological representative.

Can the absence vs. presence of an empty CV be responsible for the difference of length between rauð\#leitur ['rœyðlcit ${ }^{\mathrm{h}} \mathrm{yr}$ ] 'reddish, nom.sg. masc.' and hvít\#leitur [' $\mathrm{k}^{\mathrm{h}} \mathrm{vi}: \mathrm{t}^{\mathrm{h}}$ leit $\left.{ }^{\mathrm{h}} \mathrm{Yr}\right]$ 'whitish, nom.sg.masc.'? To generate 
this distinction, it would need to be assumed that the same derivational suffix (here -leitur) projects an empty CV only when the last consonant of the base contains $\{\mathrm{H}\}$. Let us take a look at CVCV representations of rauð\#leitur

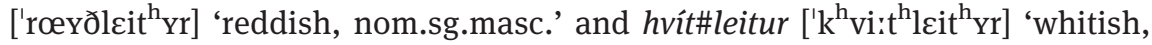
nom.sg.masc.'.

Tonic lengthening in CVCV is typically analysed as resulting from the presence of internuclear licensing on the stressed vowel. Licensing is a lateral force which eases phonetic expression. It is exerted by all phonetically expressed nuclei and, in some languages, also by Final Empty Nuclei (FENs). There are a number of ways to represent long vowels, but they will not be discussed due to their lack of relevance for the topic of this paper. ${ }^{6}$ We assume that vocalic length in Icelandic is a joint phonetic effect of two pieces of phonological information: stress and licensing.

Under the assumption that rauð\#leitur does not contain a boundary CV, we could claim that there is no representational mark for the boundary and computation runs as follows:

In Figure 3 both participating morphemes are adjacent in the representation and computation is continuous. The nucleus $\mathrm{V}_{2}$ is governed by the first vowel of the suffix $\left(V_{2}\right)$. Government has an inhibitory influence on the segments which it targets, which is why $\mathrm{V}_{2}$ is unable to provide licensing to the preceding vowel. Therefore, $V_{1}$ ends up short.

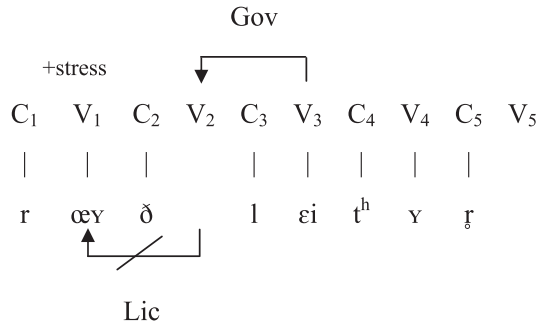

Figure 3: Representation of rauð\#leitur 'reddish, nom.sg.masc.' in Strict CV.

The configuration in Figure 3 could be juxtaposed to another one, in which an empty boundary CV is inserted. This would bring about a domino effect: the FEN of the first morpheme, $\mathrm{V}_{2}$, is ungoverned and remains laterally active. Hence it can license $V_{1}$, like in Figure 4:

6 For instance, Larsen (1998), and Scheer (2004) represent stress by an empty CV inserted immediately after the stressed vowel. 


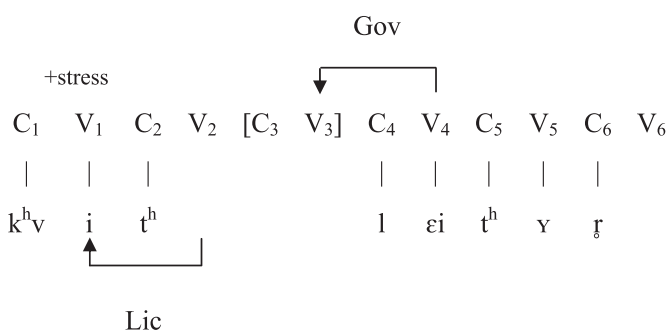

Figure 4: Representation of hvít\#leitur 'whitish, nom.sg.masc.' in Strict CV.

The representation in Figure 4 produces the desirable result - insertion of the empty CV creates a distance between the last nucleus of the first morpheme and the first nucleus of the second morpheme. We can derive a long vowel on the surface from this effect. However, there is one important aspect which still begs the question: the emptiness of $V_{2}$. This nucleus is no longer domain-final after concatenation, which is why it can be expected to be vocalised. Why is it not? The representation in Figure 4 already anticipates the system which we will argue for in the remainder of the article. We assume that Final Empty Nuclei are lexically present at the right edge of every consonant-final morpheme and they can retain their FEN status also after concatenation. Therefore, an orphan empty nucleus can remain unvocalised (and be able to govern and license itself) even though it is ungoverned. More details follow in Section 4.2.

The crucial point is that the problem with the motivation for translation of the empty CV remains, since translation cannot be dependent on a presence of a piece of melody. This is pretty much what we knew beforehand and is due to the mixed (morphosyntactic and phonological) conditioning of the phenomenon. Direct Interface as such is not the culprit here, since it was not designed for dealing with cases with mixed conditioning.

Therefore, we will pursue a different mode of interface intervention, but trying at the same time to keep in mind the most basic insight of Direct Interface: there are no diacritics in phonology. Whatever type of intervention we propose, it must make reference to the vocabulary which is used in phonological processing also in absence of morphosyntactic information. This will be our primary guidepost in the remainder of the paper.

\section{Analysis}

The conclusion which needs to be drawn from the discussion of existing and potential approaches to Icelandic post-lexical syllabification is that all of them 
are problematic, albeit each for a different reason. All syllabification algorithms which try to derive vocalic quantity from the openness of the syllable crash against the definition of a branching onset in complex forms. All accounts which take the issue of boundaries/domains into consideration are unsuccessful due to the necessity of recognizing apparent melodic conditioning for domain resolution.

Hopefully, the discussion issued so far has successfully demonstrated that both aspects are actually relevant for the pattern under discussion: the syllabic configuration (resulting from sonority relationships) and morphosyntactic information. A successful account of the problem should be able to do justice to both and integrate them into a coherent explanation.

\subsection{Theoretical preliminaries}

Before we can continue our discussion of Icelandic, it is necessary to introduce the reader to the basic operations and mechanisms used in the analysis. We propose a new variant of CVCV phonology, which combines some insights of Scheer's standard model with elements of Cyran's (2003, 2010) system.

Like in other implementations of CVCV, a fully flat phonological structure with strictly alternating C- and V-positions is assumed. Obviously not all of them need to be filled with melody, but in order for a V-slot to be empty some special conditions need to be fulfilled: it needs to be enclosed in the domain of some interconsonantal relation (more details on which follow) or be morpheme- or word-final.

Probably the most radical departure from Scheer's (2004) CVCV is that internuclear government is no longer recognized. However, internuclear licensing is preserved. It is supplemented by two types of interconsonantal relations taken from Cyran (2003, 2010): Leftward Interonset Government (LIO) and Rightward Interonset Government (RIO). LIO is responsible for establishing coda-onset clusters, whereas RIO is found in branching onsets. The presence of either relation satisfies the Empty Category Principle (ECP) of the intervening empty nucleus, i.e. allows it to remain empty. Exemplary representations of both relations are shown below (Figure 5).

In (a) $\mathrm{V}_{2}$ licences $\mathrm{C}_{2}$ to govern ( $\mathrm{GL}=$ Government-Licensing; see Charette 1990). Consequently, $C_{2}$ establishes Leftward Interonset Government with $C_{1}$, fulfilling at the same time the ECP of the intervening empty nucleus $V_{1}$. No special melodic conditions are imposed on LIO: any consonant can govern any other consonant in LIO (even though there can be language-specific 


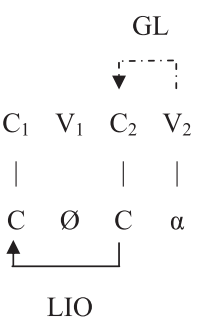

(a)

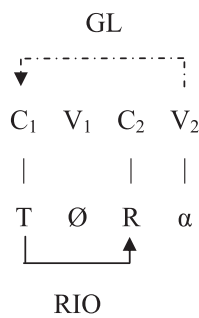

(b)
Figure 5: Interconsonantal relations. (a) A coda-onset cluster. (b) A branching onset.

restrictions). LIO subsumes thus both coda-onset and bogus clusters recognized in Standard Government Phonology, and directly corresponds to clusters which in Scheer's model enclose a governed empty nucleus.

In (b) we find a cluster of rising sonority ( $\mathrm{T}=$ Obstruent; $\mathrm{R}=$ Sonorant), which (at least in some languages) can be parsed in a different way: as a branching onset. In such a configuration, $\mathrm{V}_{2}$ non-locally licenses $\mathrm{C}_{1}$, which consequently establishes RIO with $\mathrm{C}_{2}$. Unlike LIO, RIO imposes sonority restrictions on participating consonants, which means that not any consonant can govern another consonant.

It was noticed by Kaye and Lowenstamm (1981) that branching onsets are found only in languages which also possess coda-onset clusters. The reverse is not true: languages with branching onsets and no other clusters are not on record. Following Cyran (2003, 2010), we ascribe this effect to the licensing properties of nuclei. RIO requires non-local GL, so it is inherently more difficult to license than LIO, in which the licenser affects only the immediately preceding onset. Thus, if nuclei in a given language are strong enough to license RIO, they also must be able to license LIO. Crucially, when a language allows both LIO and RIO and a given cluster can be potentially parsed as both, RIO always has priority.

All morpheme-internal consonant sequences must be syllabified as either LIO or RIO. If for some (language-specific) reason none is available, the intervening nucleus can be expected to be vocalised. However, a sequence of consonants belonging to two different morphemes has the right to remain unsyllabified, with the intervening nucleus still remaining empty due to being morpheme-final. Hence, plurimorphemic sequences can be said to contain "bogus clusters", but in contrast with SGP, there are no morpheme-internal bogus clusters. Words like atlas and athlete contain perfectly well-formed coda-onset clusters on our take.

Also, nuclei license preceding nuclei (see Zdziebko 2012; Scheer and Ziková 2010 for the source of this concept in CVCV environment). All phonetically 
expressed nuclei and, in some languages, FENs can license. Furthermore, it is assumed that vowels enclosed in RIO do not lose their licensing abilities and can still target the preceding nucleus. This is not the case with LIO, which completely extinguishes the intervening nucleus. The following figure demonstrates the discrepancy (Figure 6):

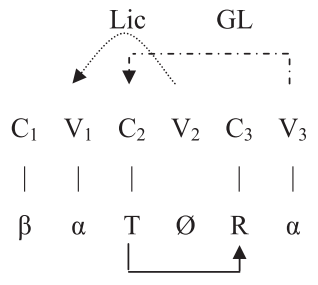

RIO

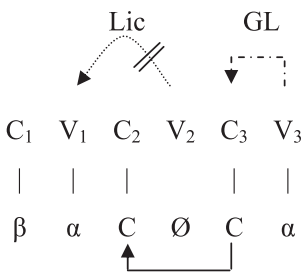

LIO
Figure 6: Vowels before RIO and LIO.

The effect of the differing influence of LIO and RIO on the intervening nucleus can be attributed to the local vs. non-local positioning of the licenser. In the case of LIO the licenser is local, so the license to govern can be "strong". Consequently, the very relation of LIO is "strong" and the intervening nucleus is completely turned off - its ECP is satisfied and its lateral skills are reduced to zero. In RIO the licenser is more distant from the governor, so this type of government is not strong and tight. The nucleus enclosed in a branching onset is not deprived of its licensing abilities and can still license the preceding nucleus.

As a result of the workings of this system of relations, all vowels before domains of LIO (i.e. in closed syllables) end up unlicensed, whereas all vowels before RIO domains (i.e. in open syllables) are licensed. Since licensing is a force which eases phonetic expression of the target, we assume it to be the main conditioning factor responsible for vowel lengthening on the surface. Open syllable lengthening is thus a phonetic effect of two phonological factors: stress and licensing.

This unconventional set of phonological relations will be used in the following analysis of postlexical syllabification in Icelandic.

\subsection{FEN upgrading}

The domain structure in Icelandic compounds and class II derivatives is the same for all of the relevant examples. That is, words like bros\#legur 'smiling, 
nom.sg.masc.', hvít\#leitur 'whitish, nom.sg.masc.', and hús\#laus 'homeless, nom.sg.masc.' share their morphosyntactic configuration with analogical derivatives with short vowels: lof\#legur 'praiseworthy, nom.sg.masc.', rauð\#leitur 'reddish, nom.sg.masc.', and von\#laus 'hopeless, nom.sg.masc.'. There is absolutely no reason to claim that they differ in morphosyntactic terms. The difference in vocalic quantity must thus be due to purely phonological effects, but at the same time our explanation should be more refined than a statement that the first group simply displays branching onsets.

Something which is worth reconsidering is whether inserting an empty CV slot is the only way in which the interface can representationally intervene. In Section 3.2. it was argued that the insertion of empty CV in all chunks displaying post-lexical syllabification faces a similar problem to the procedural approach: the motivation for translating the boundary is melodic. In order to preserve the insights and the philosophy of Direct Interface, an alternative account will be formulated, in which there will be no place for diacritics, but which will bypass the requirement of melodic conditioning.

As already indicated in Section 3.2, we propose a substantial modification of the role which Final Empty Nuclei play in the framework. In Scheer's (2004, 2012a) model empty nuclei are referred to as "Final Empty Nuclei" when they simply happen to be domain-final. In our proposal, FENs are present in the lexicon at the right edge of every consonant-final morpheme. They are assumed to be an ontologically different entity from morpheme-internal empty nuclei at all stages of phonological processing. The difference is depicted in Figure 7 on the basis of a lexical representation for the English word limp in Scheerian CVCV and in our implementation:

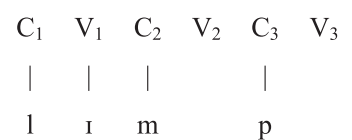

(a)

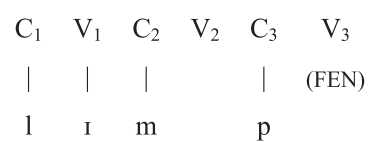

(b)

Figure 7: A FEN in the lexicon. (a) regular CVCV. (b) proposal: FEN in the lexicon.

In (a) both empty nuclei, $V_{2}$ and $V_{3}$, have the same status in the lexicon - they simply lack associated melody. However, $\mathrm{V}_{3}$ may become a FEN when it is placed at the right edge of a domain (this depends on morphosyntactic derivation). Then it is a matter of a phonological parameter whether $V_{3}$ will be governed and whether it will be able to govern and license. 
In contrast, in (b) the nucleus $\mathrm{V}_{3}$ is a different kind of phonological object from $\mathrm{V}_{2}$ already in the lexicon, since it is marked as a FEN. This status may be preserved also after concatenation takes place. This goes with all privileges characteristic of Final Empty Nuclei, like parametric government and lateral actorship (i.e. ability to exert lateral forces). In this way, there is nothing wrong with orphan empty nuclei in chunks of any size, on condition that they are morpheme-final (recall the example in Figure 4).

The behaviour of sentence- and word-internal FENs is in our proposal a locus of cross-linguistic variation and a matter of an intricate interplay of several parametric choices. For instance, a sentence-internal FEN can be parametrically governed in one language, but not in another. If it is not, it will need to be enclosed in an interconsonantal relation (contracted across the morpheme/word boundary) in order to ensure its muteness. Also, the licensing abilities of such a FEN are parametrically conditioned: it could be allowed to license consonantal relations, or to license preceding nuclei, or both, or none. It remains to be demonstrated (via a careful analysis of diverse data from various languages) whether all of these parametric choices are empirically attested. Even though parameterisation of various properties of FENs is reminiscent of Scheer's CVCV, the most crucial difference is that in our proposal FENs are formally dissociated from domain-finality.

Also, in Scheer's (2004: 489) model one of the possible interface operations was argued to be manipulation of Final Empty Nuclei. The interface was able to distribute parametric government and/or to influence lateral abilities of FENs. Later Scheer (2012a: 141) deviated from his original idea and rejected this mode of interface intervention. He claimed that government and licensing belong to computation in CVCV, and computation cannot be the output of translation of morphosyntactic information. However, we assume that operations which influence FENs are necessary on empirical grounds. Since no other explanation of Icelandic postlexical syllabification is successful, we are obliged to investigate further possibilities. It will be argued that FEN-modifying intervention can help us solve the mystery of mixed conditioning.

We propose that in some morphosyntactic configurations Icelandic Final Empty Nuclei are targeted by the interface and "upgraded". Upgrading is a cover term for operations which boost the independence of the nucleus, i.e. distribute parametric government and/or modify its lateral abilities. The process of FEN upgrading takes place during Vocabulary Insertion, which is concomitant with linearization. We subscribe to the Late Linearisation Hypothesis by Embick and Noyer (2001, 2007): 
(9) The elements of a phrase marker are linearized at Vocabulary Insertion. (Embick and Noyer 2001: 562).

It is assumed that upgraded FENs in Icelandic occur in the environments displaying symptoms of post-lexical syllabification, i.e. before a class 2 affix, in compounds, and at the end of words (as evidenced by post-lexical behaviour). Since any two adjacent words within a sentence may behave in accordance with the post-lexical syllabification algorithm regardless of the precise syntactic configuration, we posit that linearization of every morpheme different from a class 1 affix or an inflectional ending causes FEN upgrading in the preceding morpheme (of course, on condition that it does not end with a vowel).

Upgraded FENs are to a large extent independent, which means that their ECP counts as satisfied and they do not need to be enclosed in an interconsonantal relation in order to remain silent. This is unlike FENs in the contexts in which no upgrading took place, i.e. FENs before class 1 and inflectional affixes, which behave exactly like regular empty nuclei. In this way, the status of intervening empty nuclei has a direct bearing on the process of syllabification. If a sequence of two consonants hosts a regular empty nucleus, then they must contract a LIO or RIO relation in order to satisfy the ECP of the intervening V-position. But if a similar sequence hosts a FEN whose ECP counts as satisfied anyway, normally no resyllabification is necessary.

The peculiar feature of the Icelandic phonological system is that the presence of an upgraded FEN blocks resyllabification in some melodic contexts, but not in others. Namely, resyllabification across an upgraded FEN is dependent on the quality of the potential coda in the left-hand morpheme. If this coda is a sonorant or a voiced fricative (i.e. a sonorous segment), then LIO can be contracted. The consequence of LIO is that the FEN loses its inherent ability to provide the preceding nucleus with internuclear licensing. But when the potential coda is one of the four least sonorous segments $/ \mathrm{p}^{\mathrm{h}}, \mathrm{t}^{\mathrm{h}}, \mathrm{k}^{\mathrm{h}}, \mathrm{s} /$, then no resyllabification takes place, and the intervening FEN remains laterally active.

In all examples that we will provide below computation (at least syllabic computation, i.e. establishment of licensing and Interonset Government relations) operates on the whole utterance at once. It begins at the right edge of the rightmost morpheme and proceeds leftwards involving contentful nuclei, regular empty nuclei, non-upgraded FENs, and upgraded FENs. Crucially, the FEN status does not have anything to do with domain-initiality. We assume that at least in the case of Icelandic syllabification the classical 
notion of domain is redundant, since no utterance can contain more than one domain.

Let us start with an example involving a voiced consonant.

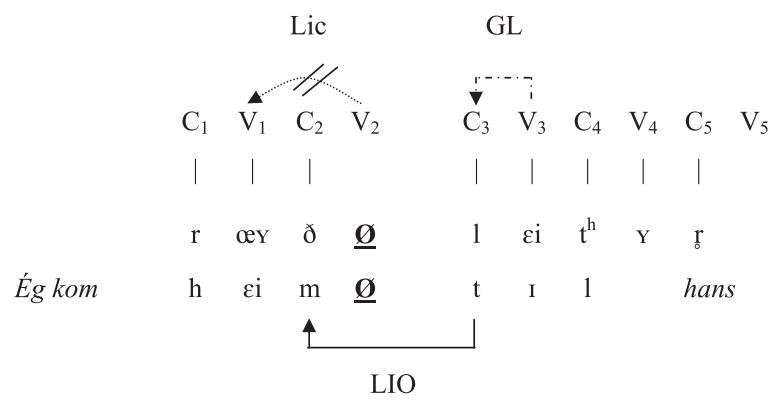

Figure 8: Post-lexical behaviour of a morpheme with a voiced consonant at the right edge.

In Figure 8 the derivation of the derivative rauðleitur 'reddish, nom.sg.masc.' is depicted, alongside the sentence Ég kom heim til hans 'I came to his house'. The nucleus $V_{3}$ government-licenses its onset $C_{3}$ to establish LIO with $C_{2}$. However, the intervening empty nucleus is not a regular empty nucleus: it has been upgraded at the interface (and marked in the representation as $\underline{\emptyset}$ ). Hence, it is by definition a more difficult obstacle for LIO to get through. Yet, since the potential governee is the voiced dental fricative /ð/ (in the case of rauðleitur), a relatively sonorous segment, the relation of LIO is successful. A dental fricative cannot be saved from being governed even if it has a shield in the form of an upgraded Final Empty Nucleus. Consonants /ð/ and /1/ still form a coda-onset cluster. Consequently, the FEN also ends up governed and is extinguished in terms of lateral activity. It cannot license the preceding stressed nucleus, so $V_{1}$ emerges as short on the surface. The same happens in the quoted sentence $-/ \mathrm{m} /$ and $/ \mathrm{t}^{\mathrm{h}} /$ can contract LIO without difficulty, causing lack of lengthening.

In contrast, consider the representation of hvitleitur 'whitish, nom.sg.masc.' and the sentence Ég tók dúk með mér 'I took a table cloth with me' (Figure 9).

The first step of derivation is the same: $V_{3}$ licenses $C_{3}$ to establish a relation. Further on, complications begin to emerge. The consonant associated with the $\mathrm{C}_{2}$ position is a fortis plosive, the least sonorous segment. It is also followed by an upgraded Final Empty Nucleus. The configuration of a fortis

7 The initial branching onset is shown as a single segment in the representation just for the sake of clarity and transparency. No claim is made that branching onsets are contour segments (even though such a solution was pursued in e.g. Rennison 1998; Lowenstamm 2003). 


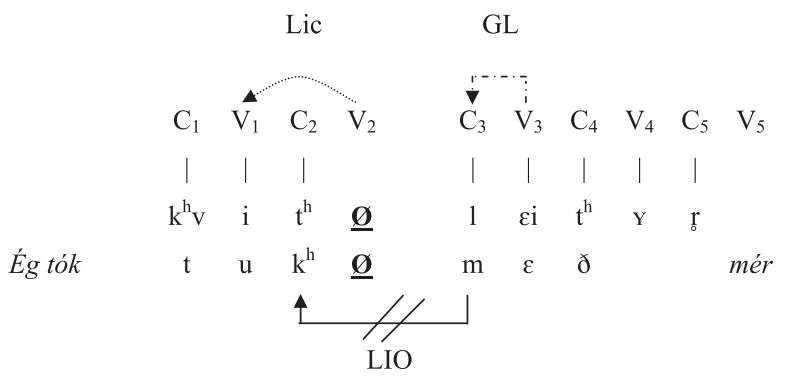

Figure 9: Postlexical behaviour of a morpheme with a fortis plosive at the right edge.

plosive guarded by an upgraded FEN turns out to be too difficult for LIO to get through. LIO fails, hence both $\mathrm{C}_{2}$ and $\mathrm{V}_{2}$ remain ungoverned. The fortis plosive associated with $\mathrm{C}_{2}$ does not sit in the coda position and therefore resists lenition: it is realised with aspiration on the surface. The FEN, $V_{2}$, also remains ungoverned, which is why its lateral abilities are unaffected. Hence, it can license the stressed nucleus, which subsequently can be interpreted as a long vowel on the surface.

The proposal issued so far explicates the distribution of vocalic length in almost all compound-initial (s)(C)(C)VC stems: the ones ending in $/ \mathrm{p}^{\mathrm{h}}, \mathrm{t}^{\mathrm{h}}, \mathrm{k}^{\mathrm{h}}, \mathrm{s} /$ and the ones ending in another consonant. The presence of an upgraded FEN is of primary importance here, since such nuclei do not call for LIO, with their ECP being satisfied even without it. Nevertheless, the needs of nuclei are not the only factor involved in the formation of clusters. Melodic factors may interact with the requirements of V-slots in various ways. In Icelandic melodic information and Final Empty Nuclei effectively conspire to produce the weird pattern at hand.

There is one more subclass of compounds, in which the vowel is long, but the stem-final consonant does not belong to the privileged group. This is true for compounds the second member of which begins with a vowel or with the glottal fricative $/ \mathrm{h} /$. It will be argued that our theory can also get a handle on these data in a straightforward manner.

Although the proposed variant of CVCV does not impose sonority criteria on the relation of LIO, the governor still needs to have some melodic content. Therefore, an empty consonantal position can never be a governor of a contentful consonantal position - it can only govern another empty C-slot. Let us take a look at the example of blóð\#eitrun ['plou:ðcit ${ }^{\text {}}{ }_{\text {ryn] }}$ ' 'blood poisoning, nom.sg.' (Figure 10).

Even though the potential governee is [ð], a sonorous segment, LIO fails because the governor is devoid of melody. Empty onsets are very bad governors. Hence, the vowel will always be long in compounds of this kind. 


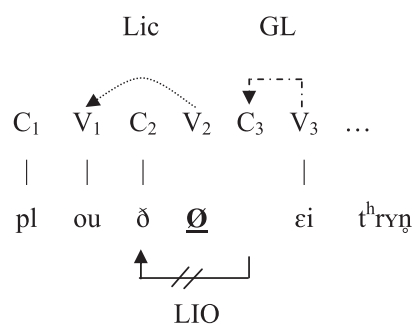

Figure 10: Representation of blóð\#eitrun 'blood poisoning, nom.sg.'.

Finally, let us turn our attention to compounds with the second member beginning with $/ \mathrm{h} /$. A representative example can be bað\#herbergi ['pa:ðherpercI] 'bathroom, nom.sg.'.

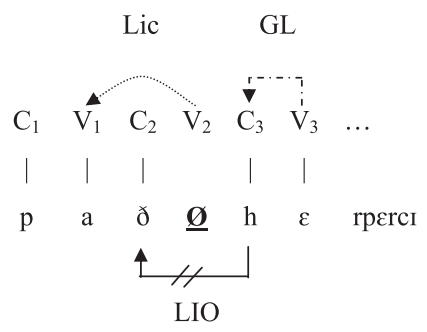

Figure 11: Representation of bað\#herbergi 'bathroom, nom.sg.'.

The explanation is evident from Figure 11. The segment $/ \mathrm{h} /$ is not strong enough to act as a governor of [ð]. For this reason, all compounds of the bað\#herbergi type are predicted to have a long vowel on the surface. Note that there are no monomorphemic words in which $/ \mathrm{h} /$ would govern anything in a coda-onset cluster. The proposal issued above explains also why such clusters fail to be established post-lexically. Note also that the upgraded FEN still plays a role in the two last examples, since it has the right to remain mute and can license the preceding vowel. A regular empty nucleus or a non-upgraded FEN would not behave like this.

An explanation based on FEN upgrading easily accounts for the difference in syllabification of the same clusters between, on the one hand, intramorphemic contexts and class I concatenation, and, on the other hand, class II concatenation. Only in the latter case does the upgrading take place, so the contrast between hekla ['hehkla] 'crochet, nom.sg.', sjúk+lingur ['sjuhklınkrr] 'patient, nom.sg.' and sjúk\#legur ['sju:k ${ }^{\mathrm{h}}$ leyrr] 'sickly, peaky, nom.sg.masc.' becomes evident. In the two former cases the underlying $/ \mathrm{k}^{\mathrm{h}} \mathrm{l} /$ can be parsed as a coda-onset cluster and the plosive is preaspirated, whereas the preceding 
vowel is in a closed syllable and does not undergo lengthening. ${ }^{8}$ The representational difference between $/ \mathrm{k}^{\mathrm{h}} \mathrm{l} /, / \mathrm{k}^{\mathrm{h}}+\mathrm{l} /$ and $/ \mathrm{k}^{\mathrm{h}} \# \mathrm{l} /$ is depicted in the following figure (Figure 12):
(a) morpheme-internal
(b) inflection / class I
(c) class II derivation /
$/ \mathrm{k}^{\mathrm{h}} 1 /$
derivation
compounding / post-
$/ \mathrm{k}^{\mathrm{h}}+\mathrm{l} /$
lexical contexts
$/ \mathrm{k}^{\mathrm{h}} \# \mathrm{l} /$

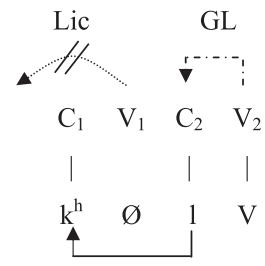
LIO

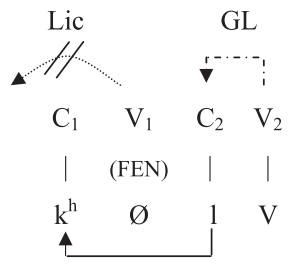
LIO

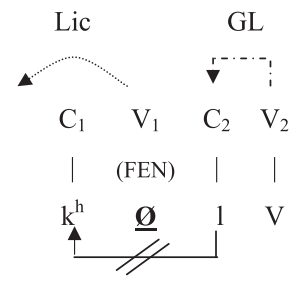
LIO

$$
\begin{gathered}
/ \mathrm{Vk}^{\mathrm{h}} \# \mathrm{l} / \rightarrow\left[\mathrm{V}: \mathrm{k}^{\mathrm{h}} \mathrm{l}\right] \\
\text { sjúk\#legur ['sju:k' }{ }^{\mathrm{h}} \text { leyrr] } \\
\text { 'sickly, peaky, } \\
\text { nom.sg.masc.' }
\end{gathered}
$$

Figure 12: Representational differences between clusters in different morphosyntactic contexts.

In example (a) we see how a morpheme-internal $/ \mathrm{k}^{\mathrm{h}} \mathrm{l} /$ cluster is parsed. Probably the first remark which needs to be made is that Icelandic cannot syllabify a word-internal cluster containing / $/$ as a branching onset: RIO is possible wordinternally only for clusters consisting of one of the segments $/ \mathrm{p}^{\mathrm{h}}, \mathrm{t}^{\mathrm{h}}, \mathrm{k}^{\mathrm{h}}, \mathrm{s} /$ followed by /j, v, r/. LIO is thus the only option. $V_{2}$ government-licences $C_{2}$ to establish LIO, and LIO succeeds. The consequences are twofold: $\mathrm{V}_{1}$ is governed and cannot license the preceding nucleus (hence no tonic lengthening) and $\mathrm{C}_{1}$ is placed in the coda position and undergoes lenition (in this case in the form of preaspiration). The fact that $/ \mathrm{k}^{\mathrm{h}} /$ does not make a good coda is still relevant,

8 We analyse secondary preaspiration (i.e. preaspiration occurring before a heavy sonorant: /1/ or a nasal) as a process of lenition of an underlying fortis plosive $/ \mathrm{p}^{\mathrm{h}}, \mathrm{t}^{\mathrm{h}}, \mathrm{k}^{\mathrm{h}} /$ induced by the coda position. Precise description of the process transcends beyond the limits of the paper. 
since it motivates lenition. LIO must take place in order to satisfy the ECP of $\mathrm{V}_{1}$, and the coda is adjusted accordingly.

In (b) the situation on the morpheme boundary is depicted. The cluster does not enclose a regular empty nucleus - it encloses a FEN. However, this in itself does not constitute a problem, since the class I suffix -lingur is assumed not to exert any influence on the root at the point Vocabulary Insertion and linearization takes place. The FEN is left ungoverned and calls for being enclosed in an interconsonantal relation regardless of being a FEN. It patterns with regular empty nuclei and does not influence the normal course of phonological computation. An underlying $/ \mathrm{k}^{\mathrm{h}} /$ guarded by a non-upgraded FEN is computed in the same way as $/ \mathrm{k}^{\mathrm{h}} /$ followed by a regular internal empty nucleus would be.

Only in (c) does computation proceed differently, since its input is also different: suffix -legur is merged at a node which translates into the operation of FEN upgrading during Vocabulary Insertion. The presence of an upgraded FEN results in the non-parsability of the resulting structure as a potential LIO domain during computation. The ECP of $\mathrm{V}_{1}$ being satisfied anyway, the system chooses not to enforce lenition on $\mathrm{C}_{1}$ to accommodate it in the coda. There is no motivation for resyllabification. A failed LIO results in tonic lengthening on the surface.

It is possible that FENs in some other language could behave like Icelandic FENs without upgrading at the interface, i.e. it would always be ungovernable and not only in selected morphosyntactic contexts. However, in Icelandic we need to distinguish between class 1 and class 2 affixation: in the case of the former the FEN of the stem behaves like a regular morpheme-internal empty nucleus, whereas in the case of the latter the boundary seems to be "stronger" due to the FEN being parametrically governed. This is why the properties of FENs need to be placed under strict morphosyntactic control.

The system described above can work only if we assume that coda-onset clusters are established by means of an interconsonantal relation, like LIO. The Icelandic pattern provides us with evidence for the communication between both members of the cluster, casting doubt on the relevance of Scheer's (2004) assumption that all coda-onset cluster are actually bogus, i.e. that they enclose a properly governed nucleus and there is no phonological relation unifying both members. ${ }^{9}$

\footnotetext{
9 Further evidence for the LIO approach and against the non-communication hypothesis could be adduced from the syllable contact phenomena in languages like Kazakh (Davis 1998; Gouskova 2004): the post-coda consonant in Kazakh undergoes fortition, but only to the extent which allows it to be stronger than the coda consonant. The pattern is way too fine-grained to be captured by the Coda Mirror prediction "post-coda is strong, coda is weak", even when we assume two-legged sonorants (Ségéral and Scheer 2008).
} 
To sum up this section, it is worth pointing out that the tools we have developed enable us to successfully combine both factors relevant for the process of Icelandic postlexical syllabification: morphosyntactic information and the melodic structure of participating consonants. In this regard the proposal stands in sharp contrast with other existing accounts.

However, there are some inherent similarities between FEN upgrading and the alternative explanations discussed earlier. For instance, Gussmann's (1985) boundary weakening is reminiscent of FEN upgrading, although we strengthen the boundary. The crucial difference is that Gussmann's boundaries were diacritics, whereas Final Empty Nuclei are true phonological objects. Also, boundary weakening was a phonological rule, whereas FEN upgrading takes place during spell-out and linearisation and precedes phonological computation proper. Finally, Gussmann's (1985) boundary weakening was conditioned by a phonological environment, whereas FEN upgrading takes place in morphosyntactically defined settings.

There is also a correlation between the present proposal and Gussmann (2002). The clusters found in compounds and class II derivatives were always syllabified as bogus clusters by Gussmann (2002) and we adopt a similar stance. However, the details differ significantly since Gussmann's SGP recognizes bogus clusters also within morphemes and subscribes to syllabic structure specified in the lexicon. On our take syllabification is dynamic, and typically there are only two ways a syllabification algorithm may parse a cluster: as a coda-onset cluster (establishing LIO) and as a branching onset (with RIO). A thing like a "bogus cluster" may exist only on a morpheme or word boundary, where FEN upgrading makes it impossible for the algorithm to establish either type of relation.

Probably the biggest advantage of the present proposal over Gussmann (2002) is that we do not need to resort to allomorphy in order to explain alternation of vocalic quantity and consonantal changes in forms like hvít [k $\mathrm{k}^{\mathrm{h}}$ vi: $\left.\mathrm{t}^{\mathrm{h}}\right]$ 'white, nom.sg.fem.' $\sim$ hvitt [ $\mathrm{k}^{\mathrm{h}}$ viht] 'white, nom.sg.neut.' and vaka ['va:k ${ }^{\mathrm{h}} \mathrm{a}$ ] 'to be awake' vakti ['vaxtI] 'I was awake'. As already indicated above, Gussmann's model, which operated on one level of representation, enforced recognition of massive allomorphy - each pair of forms which displayed a difference in vowel length had to map onto two distinct phonological representations. We posit that alternations of vowel length are a purely phonological phenomenon, as are the processes of spirantisation and preaspiration. Furthermore, our approach clearly explains the two-way syllabification of /s/: it forms a coda when an upgraded FEN does not intervene (preceding vowel short, as in taska 'bag'); otherwise, it remains ungoverned (preceding vowel long, as in bros\#legur 'smiling'). 


\section{Final remarks}

The paper introduced a novel approach to the distribution of vocalic quantity in Icelandic compounds, derivatives of class II and in postlexical contexts. It was argued that all of the existing approaches to the phenomenon are riddled with flaws and that a new explanation is necessary.

We have made a series of original assumptions concerning the structure of phonological representations and the inventory of interface operations. We assumed the constituent structure of CVCV, but we put forward that codaonset clusters need to be created by means of interconsonantal relations (LIO and RIO), rather than host a properly governed empty nucleus. It was also proposed that FENs are marked as FENs in the lexicon and retain this status at all derivational stages. At the same time we rejected the correlation between the presence of a FEN and the right edge of a domain. We also revived Scheer's (2004) proposal of FEN manipulation as a possible interface operation. FEN upgrading, i.e. distribution of parametric government and modification of the lateral skills of empty nuclei, may directly influence syllabification across word- and morpheme-boundaries, because it eliminates the main reason for contracting a relation: satisfying the ECP of the intervening nucleus.

What still remains to be settled is to what extent the proposed model can be generalised to the analysis of other languages. If it is possible to have FENs also within the computational domain and not only at its right edge, there are many effects which can be explained with reference to them. For instance, the presence of a FEN on a root-suffix boundary can be argued to be responsible for some derived environment effect. FENs may be also assumed to block application of melodic phonological processes - a given feature can spread across regular empty nuclei, but not across FENs. FEN manipulation constitutes a valuable extension of the repertoire of representational tools available in the analysis of interface phenomena.

Acknowledgments: I would like to express my deepest gratitude to the three anonymous TLR reviewers for many thought-provoking remarks, which significantly raised the quality of the paper. I also thank Péter Szigetvári, Sławomir Zdziebko, Connor Youngberg and the participants of GPRT 9 (Budapest), LAGB 2013 meeting (London), and RTS (Paris) for providing feedback on earlier versions of the analysis presented in the paper. Obviously, all shortcomings are only mine. 


\section{References}

Árnason, Kristján. 1980. Quantity in Historical Phonology: Icelandic and Related Cases. Cambridge: Cambridge University Press.

Árnason, Kristján. 1998. Vowel shortness in Icelandic. In Wolfgang Kehrein \& Richard Wiese (eds.), Phonology and morphology of Germanic languages, 3-25. Tübingen: Max Niemeyer Verlag.

Árnason, Kristján. 2011. The phonology of Icelandic and Faroese. Oxford: Oxford University Press.

Backley, Phillip. 2011. An Introduction to Element Theory. Edinburgh: Edinburgh University Press.

Bermúdez-Otero, Ricardo. 2011. Cyclicity. In Marc van Oostendorp, Colin J. Ewen, Elizabeth Hume \& Keren Rice (eds.), The Blackwell companion to phonology. Vol. 4: Phonological interfaces, 2019-2048. Malden, MA: Wiley-Blackwell.

Booij, Geert. 1986. Icelandic vowel lengthening and prosodic phonology. In Frits H. Beukema \& Aafke Hulk (eds.), Linguistics in the Netherlands 1986, 9-18. Dordrecht: Foris.

Botma, Bert. 2008. Aspiration, fricatives, and the multiple features hypothesis in Icelandic. Paper presented at Meertens Institute, 11 September.

Charette, Monik. 1990. Licence to govern. Phonology 7. 233-253.

Chomsky, Noam. 1965. Aspects of the theory of syntax. Cambridge, MA: MIT Press.

Chomsky, Noam \& Morris Halle. 1968. The sound pattern of English. New York: Harper \& Row. Chomsky, Noam. 2001. Derivation by phase. In Michael Kenstowicz (ed.), Ken Hale: Life in Language, 1-52. Cambridge, MA: MIT Press.

Cyran, Eugeniusz. 2003. Complexity scales and licensing strength in phonology. Lublin: KUL. Cyran, Eugeniusz. 2010. Complexity scales and licensing in phonology. Berlin: Mouton de Gruyter.

Czarnecki, Przemystaw. 2013. The phonology of quantity in Icelandic and Norwegian. Poznań: Adam Mickiewicz University dissertation.

Davis, Stuart. 1998. Syllable contact in optimality theory. Korean Journal of Linguistics 23. 181-211.

Einarsson, Stefán. 1945. Icelandic. grammar, texts, glossary. Baltimore: The Johns Hopkins Press.

Embick, David \& Rolf Noyer. 2001. Movement operations after syntax. Linguistic Inquiry 32. 555-595.

Embick, David \& Rolf Noyer. 2007. Distributed morphology and the syntax-morphology interface. In Gillian Ramchand \& Charles Reiss (eds.), The oxford handbook of linguistic interfaces, 289-324. Oxford: OUP.

Fodor, Jerry A. 1983. Modularity of Mind: An Essay on Faculty Psychology. Cambridge, Mass.: MIT Press.

Fortuna, Marcin. 2013. Icelandic vowel length and representational theories of phonology. In Balázs Surányi (ed.), Proceedings of the second Central-European conference in linguistics for postgraduate students, 88-108. Budapest: Pázmány Péter Catholic University.

Gouskova, Maria. 2004. Relational hierarchies in optimality theory: The case of syllable contact. Phonology 21(2). 201-250.

Guðfinnsson, Björn. 1946. Mállýzkur I. Reykjavík: Îsafoldarprentsmiðja.

Gussmann, Edmund. 1985. The morphology of a phonological rule: Icelandic vowel length. In Edmund Gussmann (ed.), Phono-morphology: Studies in the interaction of phonology and morphology, 75-94. Lublin: RW Katolickiego Uniwersytetu Lubelskiego. 
Gussmann, Edmund. 2002. Phonology: analysis and theory. Cambridge: CUP.

Gussmann, Edmund. 2006a. Icelandic vowel length and governing relations in phonology. Lingua Posnaniensis XLVIII. 21-41.

Gussmann, Edmund. 2006b. Icelandic and universal phonology. Greifswald: Ernst-Moritz-Arndt Universität Greifswald.

Haugen, Einar. 1958. The phonemics of modern Icelandic. Language 34. 55-88.

Halle, Morris \& Alec Marantz. 1994. Some key features of Distributed Morphology. In Andrew Carnie \& Heidi Harley (eds.), MITWPL 21: Papers on phonology and morphology, 275-288. Cambridge, Mass.: MITWPL.

Harris, John. 1994. English sound structure. Oxford: Blackwell.

Kaye, Jonathan. 1995. Derivations and interfaces. In Jacques Durand \& Francis Katamba (eds.), Frontiers of phonology: Atoms, structures, derivations, 289-332. London: Longman Linguistics Library.

Kaye, Jonathan \& Jean Lowenstamm. 1981. Syllable structure and markedness theory. In Adriana Belletti, Luciana Brandi \& Luigi Rizzi (eds.), Theory of markedness in generative grammar. Proceedings of the 1979 GLOW conference, 287-315. Pisa: Scuola normale superiore.

Kiparsky, Paul. 1984. On the lexical phonology of Icelandic. In Claes Cristian Elert, Irène Johansson \& Eva Strangert (eds.), Nordic prosody III. Papers from a symposium, 135-164. Stockholm: Almqvist \& Wiksell.

Kiparsky, Paul. 1998. Paradigm effects and opacity. Ms. Stanford, CA: Stanford University.

Larsen, Uffe Bergeton. 1998. Vowel length, Radoppiamento Sintattico and the selection of the definite article in modern Italian. In Patrick Sauzet (ed.), Languages et grammaires II \& III: phonologie, 87-102. Paris: Université de Paris 8.

Lowenstamm, Jean. 1999. The beginning of the word. In John R. Rennison \& Klaus Kühnhammer (eds.), Phonologica 1996: Syllables !?, 153-166. The Hague: Thesus.

Lowenstamm, Jean. 2003. Remarks on Mutae cum Liquida and Branching Onsets. In Stefan Ploch (ed.), Living on the Edge: 28 Papers in Honor of Jonathan Kaye, 339-363. Berlin/New York: Mouton de Gruyter.

Murray, Robert W. \& Theo Vennemann. 1983. Sound change and syllable structure. Language 59(3). 514-528.

Nespor, Marina \& Irene Vogel. 1986. Prosodic phonology. Dordrecht: Foris.

Pak, Majorie 2008. The postsyntactic derivation and its phonological reflexes. Philadelphia, PA: University of Pennsylvania dissertation.

Rennison, John R. Contour segments with subsegmental structures. In Eugeniusz Cyran (ed.), Structure and Interpretation: Studies in Phonology, 227-245. Lublin: Folium.

Samuels, Bridget 2009. The structure of phonological theory. Cambridge, MA: Harvard University dissertation.

Scheer, Tobias. 2004. A lateral theory of phonology. volume I: What Is CVCV, and why should it be? Berlin: Mouton de Gruyter.

Scheer, Tobias. 2011. A guide to morphosyntax-phonology interface theories. How extra-phonological information is treated in phonology since Trubetzkoy's Grenzsignale. Berlin: Mouton de Gruyter.

Scheer, Tobias. 2012a. Direct interface and one-channel translation. A non-diacritic theory of morphosyntax-phonology interface. Berlin: Mouton de Gruyter.

Scheer, Tobias. 2012b. At the right edge of words (again). McGill Working Papers in Linguistics 22(1). 1-28. 
Scheer, Tobias \& Markéta Ziková. 2010. The coda mirror V2. Acta Linguistica Hungarica 57(4). 411-431.

Ségéral, Philippe \& Tobias Scheer. 2008. The Coda Mirror, stress and positional parameters. In Joaquim Brandão de Carvalho, Tobias Scheer \& Philippe Ségéral (eds), Lenition and Fortition, 483-518. Berlin/New York: Mouton de Gruyter.

Vennemann, Theo. 1972. On the theory of syllabic phonology. Linguistische Berichte 18. 1-18. Zdziebko, Stawomir. 2012. Issues in Scottish vowel quantity. Newcastle upon Tyne: Cambridge Scholars Publishing. 